\title{
Corneal thickness in eyes with diabetic and nondiabetic neovascularisation
}

\author{
THOMAS OLSEN AND NIELS BUSTED
}

From the Department of Ophthalmology, University of Aarhus, Aarhus Kommunehospital, DK-8000 Aarhus C, Denmark

SUMMARY The corneal thickness was measured in 20 patients with ocular neovascularisation of diabetic and nondiabetic aetiology. Mean corneal thickness $( \pm \mathrm{SD})$ was $0.561 \mathrm{~mm}( \pm 0.027)$ and $0.499 \mathrm{~mm}( \pm 0.029)$ in the diabetic $(n=11)$ and the nondiabetic groups $(n=9)$, respectively $(2 p$ $<0.001)$. The increased corneal thickness in the diabetic group is comparable to that previously reported in diabetics with proliferative retinopathy. These results indicate that the increased corneal thickness found in diabetics is peculiar to the diabetic eye and not secondary to the process of ocular neovascularisation as such.

Increased corneal thickness has recently been reported in diabetic patients. Furthermore, it was shown that the corneal thickness of diabetics with retinal proliferations was higher than in diabetics without these changes. ${ }^{1}$

The cause of the increased corneal thickness is unknown. The association with retinal proliferations may suggest a neovascular factor, whatever its nature may be, reflecting its presence in the corneal thickness.

To investigate whether neovascularisation as such was a significant factor we decided to study the corneal thickness in patients with neovascularisation of diabetic as well as nondiabetic origin.

\section{Subjects and methods}

Twenty patients previously admitted to the eye department because of haemorrhagic glaucoma were examined. This group comprised 11 diabetics and 9 patients with previous occlusion of the retinal vessels. All of the diabetics were insulin-dependent. Age and disease duration are shown in Table 1 .

The patients were examined 4 months to 2 years after last discharge from the hospital. The eye examination included slit-lamp gonioscopy and fundus examination. In some cases where the intraocular examination was hindered owing to cataract or a cloudy cornea, information on the state of neovascularisation was obtained from previous notes in the case record.

Correspondence to Thomas Olsen, MD.
The corneal thickness was measured as described earlier. ${ }^{1}$ Intraocular pressure (IOP) was measured with an applanation tonometer attached to the slitlamp. No corrections were made for the corneal thickness.

\section{Results}

The crude data on IOP and corneal thickness appear in Table 1, in which the state of neovascularisation is given. Neovascularisation of the iris in this table means rubeosis iridis and/or vessels in the chamber angle.

Four eyes, all in the diabetic patients, were found to be in a phthisic involution. The mean corneal thickness $( \pm \mathrm{SD})$ in these previous glaucomatous eyes was $0.695 \mathrm{~mm}( \pm 0.042)$. To compare the corneal thickness in the diabetic patients with that in the nondiabetics the corneal thicknesses of the nonphthisic eyes (also with neovascularisation) in these patients were grouped with the corneal thicknesses of the high-pressure side in the rest of the diabetics and compared with the corneal thicknesses of the glaucomatous side of the nondiabetics. The resulting mean values $( \pm S D)$ were $0.561 \mathrm{~mm}( \pm 0.036)$ and $0.499 \mathrm{~mm}( \pm 0.029)$ for the diabetics and the nondiabetics, respectively $(2 \mathrm{p}<0.001$ by unpaired $t$ test). No significant correlation between IOP and corneal thickness was found in either group or in the 2 groups combined (Fig. 1). 
Table 1 Central corneal thickness (CCT) and other clinical data in patients with neovascularisation of diabetic and nondiabetic origin

\begin{tabular}{|c|c|c|c|c|c|c|c|c|}
\hline \multirow[t]{3}{*}{ Case } & \multirow[t]{3}{*}{ Age/sex } & \multirow[t]{3}{*}{ Diagnosis } & \multirow{3}{*}{$\begin{array}{l}\text { IOP }(\mathrm{mmHg}) \\
\text { right/left }\end{array}$} & \multirow{3}{*}{$\begin{array}{l}C C T(\mathrm{~mm}) \\
\text { right/left }\end{array}$} & \multicolumn{4}{|c|}{ Neovascularisation } \\
\hline & & & & & \multicolumn{2}{|c|}{ Right eye } & \multicolumn{2}{|c|}{ Left eve } \\
\hline & & & & & Iris & Retina & Iris & Retina \\
\hline 1 & $47 / f$ & $\mathrm{DM} 47 \mathrm{yr}$ & $12 / 18$ & $0 \cdot 540 / 0 \cdot 545$ & + & + & - & + \\
\hline 2 & $78 / \mathrm{f}$ & $\mathrm{DM} 30 \mathrm{yr}$ & $19 / 33$ & $0 \cdot 530 / 0 \cdot 540$ & - & - & + & + \\
\hline 3 & $41 / m$ & $\mathrm{DM} 28 \mathrm{yr}$ & $19 / 17$ & $0.530 / 0 \cdot 555$ & + & + & - & + \\
\hline 4 & $35 / \mathrm{f}$ & $\mathrm{DM} 25 \mathrm{yr}$ & $18 / 30$ & $0.625 / 0.650$ & - & + & + & + \\
\hline 5 & $26 / m$ & $\mathrm{DM} 24 \mathrm{yr}$ & $-/ 16$ & $-/ 0 \cdot 555$ & \multicolumn{2}{|c|}{ (Enucl.) } & + & + \\
\hline 6 & $44 / m$ & $\mathrm{DM} 23 \mathrm{yr}$ & $5 / 16$ & $0.650 / 0 \cdot 520$ & $+^{*}$ & + & - & + \\
\hline 7 & $45 / \mathrm{m}$ & $\mathrm{DM} 20 \mathrm{yr}$ & $39 / 17$ & $0 \cdot 570 / 0 \cdot 510$ & + & + & - & + \\
\hline 8 & $32 / \mathrm{m}$ & $\mathrm{DM} 16 \mathrm{yr}$ & $0 / 12$ & $0 \cdot 680 / 0 \cdot 540$ & $+^{*}$ & + & + & + \\
\hline 9 & $73 / f$ & $\mathrm{DM} 11 \mathrm{yr}$ & $17 /-$ & $0.575 /-$ & + & + & \multicolumn{2}{|c|}{ (Exent.) } \\
\hline 10 & $35 / f$ & $\mathrm{DM} 14 \mathrm{yr}$ & $0 / 16$ & $0 \cdot 700 / 0 \cdot 585$ & $+^{*}$ & + & + & + \\
\hline 11 & $79 / \mathrm{m}$ & $\mathrm{DM} 4 \mathrm{yr}$ & $34 / 5$ & $0.565 / 0 \cdot 750$ & + & + & $+^{*}$ & + \\
\hline 12 & $76 / f$ & V. thromb. & $24 / 14$ & $0 \cdot 510 / 0 \cdot 510$ & + & - & - & - \\
\hline 13 & $75 / f$ & V. thromb. & $56 /-$ & $0.440 /-$ & + & - & \multicolumn{2}{|c|}{ (Enucl.) } \\
\hline 14 & $76 / \mathrm{m}$ & V. thromb. & $52 / 19$ & $0.535 / 0.520$ & + & + & - & - \\
\hline 15 & $73 / \mathrm{m}$ & V. thromb. & $26 / 16$ & $0.530 / 0.525$ & + & + & - & - \\
\hline 16 & $75 / \mathrm{m}$ & V. thromb. & $16 / 43$ & $0 \cdot 515 / 0 \cdot 510$ & - & - & + & - \\
\hline 17 & $67 / \mathrm{m}$ & V. thromb. & $16 / 50$ & $0.525 / 0.515$ & - & - & + & - \\
\hline 18 & $67 / \mathrm{m}$ & V. thromb. & $26 / 16$ & $0 \cdot 480 / 0 \cdot 485$ & + & - & + & - \\
\hline 19 & $80 / m$ & V. thromb. & $20 / 27$ & $0 \cdot 500 / 0 \cdot 490$ & - & - & + & - \\
\hline 20 & $75 / \mathrm{m}$ & V. thromb. & $38 / 16$ & $0 \cdot 485 / 0 \cdot 500$ & + & - & - & - \\
\hline
\end{tabular}

*Phthistic eve. $\mathrm{DM}=$ diabetes mellitus. $\mathrm{V}$. thromb. =venous thrombosis. Enucl. = enucleation. Exent. = exenteration.

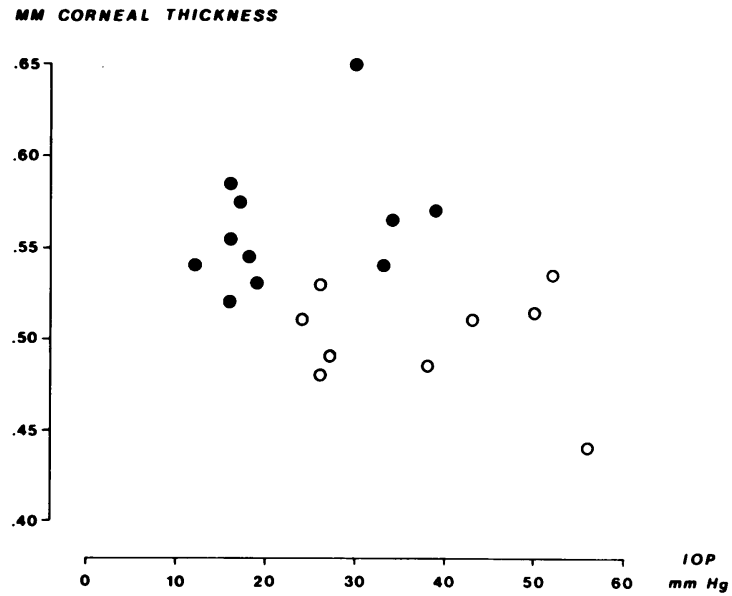

Fig. 1 Central corneal thickness plotted against intraocular pressure (IOP) in 11 diabetics (closed circles) and 9 nondiabetics (open circles). Coefficient of correlation, $r=+0.33$ and $-0 \cdot 17$, respectively (not significantly different from zero in either group).

\section{Discussion}

The corneal thickness in this series of diabetic patients is comparable to the corneal thickness previously reported in diabetic patients with proliferative retinopathy. ${ }^{1}$ But the corneal thickness of the nondiabetic eyes with neovascularisation was found to be in the normal range. This suggests that the cause of the augmented corneal thickness in the diabetics is not to be sought among factors secondary to the process of neovascularisation as such. This conclusion is made on the assumption that the new vessel formation, whether this is caused by ischaemia or other factors, is similar in the diabetic and the nondiabetic condition. ${ }^{2}$

The average age of the nondiabetics was higher than that of the diabetics. Most authors agree that above the age of 15 , the central thickness is not significantly influenced by age. ${ }^{3}$ One study has reported a corneal thinning with age, predominantly in males, in a Greenland Eskimo population. ${ }^{4}$ No significant thinning was observed in 98 Danes. However, even if the values for the male Eskimos were used for correction of the present data, the difference between the mean thickness of the diabetic and nondiabetic group was still significant at the 0.01 level. Therefore it is very unlikely that age has affected the present results.

As a group the intraocular pressure of the nondiabetic eyes turned out to be higher than that of the diabetics. With a normally functioning endothelium the IOP may be expected to decrease the corneal thickness. ${ }^{356}$ However, as may be seen from Fig. 1, the IOP did not account for the observed differences between the corneal thickness of diabetic and nondiabetic subjects. If anything, the corneal thickness of the diabetics may be seen to show an upward tendency with increasing IOP. 


\section{References}

1 Busted N. Olsen T. Schmitz O. Clinical observations on the corneal thickness and the corneal endothelium in diabetes mellitus. Br J Ophthalmol 1981; 65: 687-90.

2 Garner A. The pathogenesis of ocular neovascularisation. Bibl Anat 1977; 16: 14-8.

3 Mishima S. Corneal thickness. Surv Ophthalmol 1968; 13: 57-96.
4 Alsbirk PH. Corneal thickness I. Age variation, sex difference and oculometric correlations. Acta Ophthalmol (Kbh) 1978; 56: 95-101.

5 Ehlers N. On corneal thickness and intraocular pressure II. Acta Ophthalmol (Kbh) 1970; 48: 1107-12.

6 Olsen T. The endothelial cell damage in acute glaucoma. On the corneal thickness response to intraocular pressure. Acta Ophthalmol (Kbh) 1980; 58: 257-66. 